\title{
A magia dos sertões desperta o Brasil
}

\author{
MARCO ANTÔNIO COELHO
}

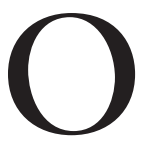

CINQÜENTENÁRIO da publicação do livro clássico de Guimarães Rosa deu um considerável impulso à promoção de dezenas de empreendimentos que giram em torno da vida brasileira, perdida nas vastidões das lonjuras de um país ainda não totalmente devassado. Realidade que é uma herança secular que vai sendo solapada por um progresso que introduz modernidades, que modificam injustiças sem atingir o cerne das desgraças.

A resultante dessa inundação de histórias de tempos idos e vividos não é apenas uma recordação de fatos ainda insepultos. O resgate de dados de nossa formação cultural indica o que necessitamos vir a ter - maior identidade com a natureza e com a gente simples do povo.

\section{O circuito Guimarães Rosa}

A movimentação em torno da obra do autor de Grande sertão: veredas vai se espraiando na intelectualidade brasileira e desperta cada vez mais o interesse dos estudantes. Uma das razões para a visível procura dos romances e contos desse escritor resulta de inúmeras iniciativas no chamado "Circuito Guimarães Rosa", em Minas Gerais, na região localizada entre o São Francisco e o Rio das Velhas. Esse circuito, cujo núcleo é situado na cidade de Cordisburgo, terra natal do escritor, recebe um valioso apoio de duas instituições. A primeira delas é o Museu Casa de Guimarães Rosa, organizado em 1974 pelo governo mineiro. É um órgão subordinado à Secretaria Estadual da Cultura e seu atual diretor é o professor Ronaldo Alves de Oliveira, docente de História no ginásio de Cordisburgo.

A divulgação da literatura de Guimarães Rosa apóia-se sobretudo na Associação dos Amigos do Museu, fundada em dezembro de 1994, quando se evidenciou a necessidade de uma organização não-governamental para transformá-lo num centro de pesquisa e para organizar eventos em torno da obra do escritor. Ao mesmo tempo, a Associação recebeu o encargo de também incentivar a participação nas iniciativas do Museu da comunidade de Cordisburgo e das cidades vizinhas.

Para cumprir esses objetivos, a Associação concentrou-se em alguns trabalhos. Dedicou-se com maior empenho a fim de aumentar o acervo da "Biblioteca Riobaldo e Diadorim" e para ampliar a freqüência dos que ali buscam ampliar seus conhecimentos. Quatro anos atrás, a Associação conseguiu a doação de 2.600 livros do Ministério da Cultura, e atualmente essa biblioteca possui cerca de dez mil livros. 
A entidade presta um apoio decisivo às "semanas roseanas", organizadas anualmente pela Academia Cordisburguense de Letras. Essas comemorações desde 1989 são realizadas com enorme sucesso.

Nas "semanas roseanas" são promovidas em Cordisburgo as seguintes atividades: mesas-redondas com a participação de pesquisadores provenientes de centros acadêmicos (especialmente USP, UFMG, PUC-MG); oficinas literárias, de música, bordado e desenho; apresentações teatrais, lançamentos de livros, feiras de artesanato etc.

Um ponto alto nessa programação são as "Caminhadas eco-literárias", que percorrem locais rurais e urbanos citados nas obras de Guimarães Rosa, realizações que permitem aos participantes conhecer os cerrados e a cultura do sertão, meticulosamente apresentados no Grande sertão: veredas.

As "semanas roseanas" tornaramse eventos que não somente mobilizam a população da antiga Vista Alegre, hoje Cordisburgo - a "cidade do coração". Elas são aguardadas com enorme expectativa nas cidades vizinhas e pelos amantes da literatura de Guimarães Rosa. Na 18 a "semana roseana", em julho passado, estiveram presentes mais de dois mil visitantes. Para recebê-los, seguindo um projeto do Grupo dos Iabas, a prefeitura, apoiada pela Associação dos Amigos, mobilizou os estudantes a fim de serem confeccionadas quinze mil rosas vermelhas, de papel crepom, para decorar praças, igrejas e ruas principais da cidade, seguindo o lema - "Rosas para o Rosa".
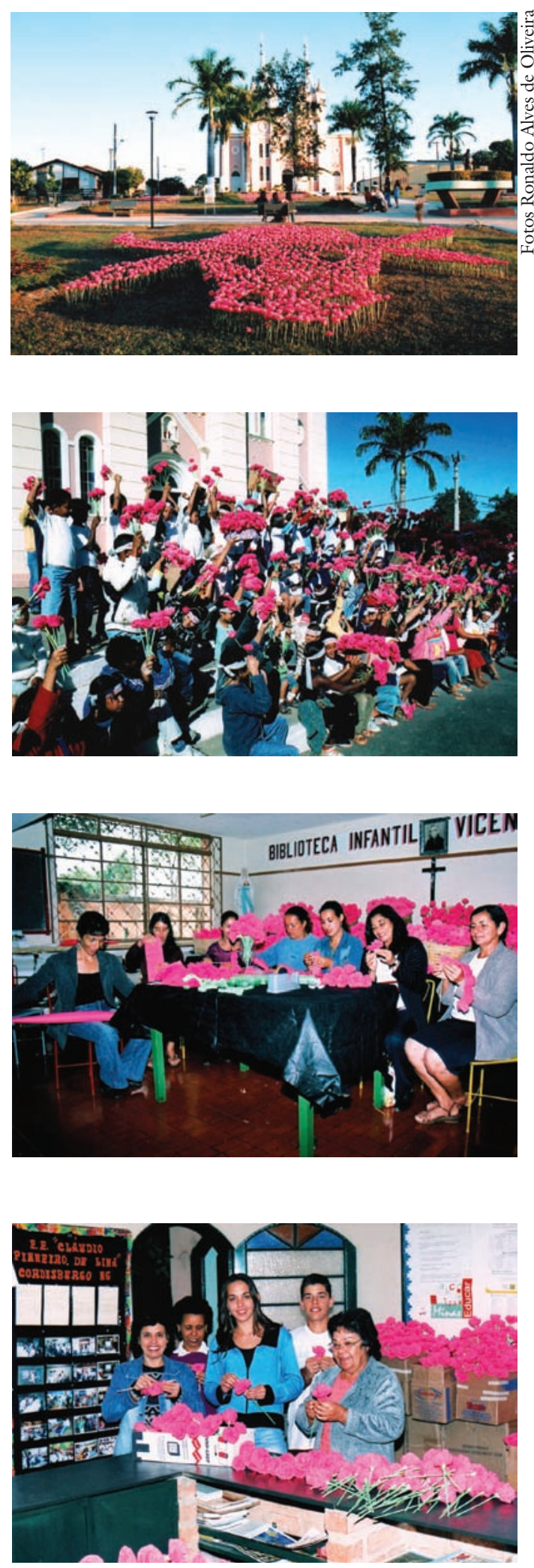

Cordisburgo decorada por 15 mil rosas preparadas nas escolas e pelos estudantes. 
Segundo a professora Silvânia Sousa do Nascimento, da Superintendência dos Museus da Secretaria Estadual da Cultura, "em conseqüência do infatigável e entusiasmado trabalho da Associação dos Amigos, a casa de Guimarães Rosa passou a ser o mais visitado museu em Minas Gerais".

O trabalho em torno das obras do grande escritor é feito também em outras cidades do Meio-Norte e do Norte de Minas Gerais, particularmente naquelas incluídas no circuito Guimarães Rosa. Em Morro da Garça, por exemplo (cenário do conto "O recado do morro", no livro Corpo de baile) foi criada há três anos a Casa da Cultura do Sertão, que atua para valorizar as tradições dos sertanejos. Entre suas atividades, destaca-se o sucesso da oficina "Estórias bordadas e tecidas". Em Andrequicé, cenário dos contos "Uma estória de amor" e "Dão-Lalalão", foi montado o Museu Manuelzão, em que se presta uma homenagem especial ao vaqueiro, que, além de ter acompanhado Guimarães Rosa em suas pesquisas, foi imortalizado pelo escritor em alguns de seus contos. Assim, além de barquejadas organizadas para percorrer o Rio São Francisco e seus afluentes, em Araçaí, Várzea da Palma, Lassance, Buritizeiro, Três Marias e em outros municípios, pode-se relembrar aquela vivência fielmente descrita pela beleza e a originalidade da prosa do autor de Grande sertão: veredas.

\section{Os contadores de estórias}

O Grupo de Contadores de Estórias Miguilim completou dez anos em 2006. Foi criado pela médica Calina
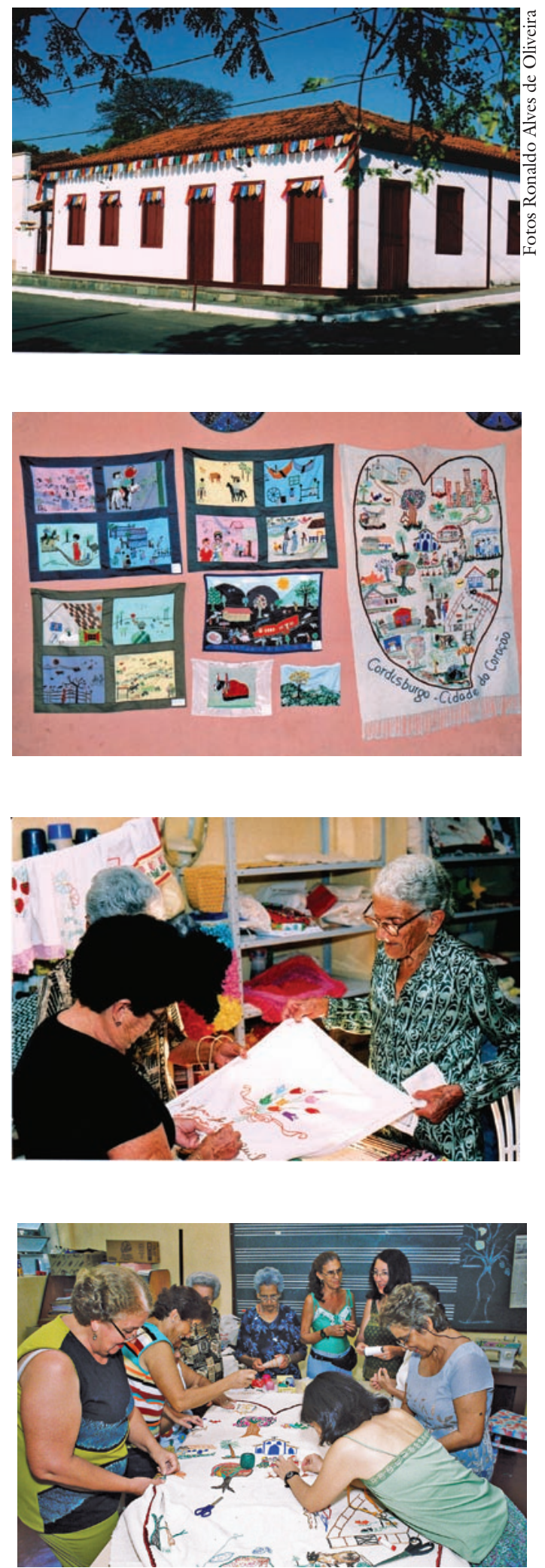

Musen Guimarães Rosa, bordados e desenhos preparados pelas artesãs. 


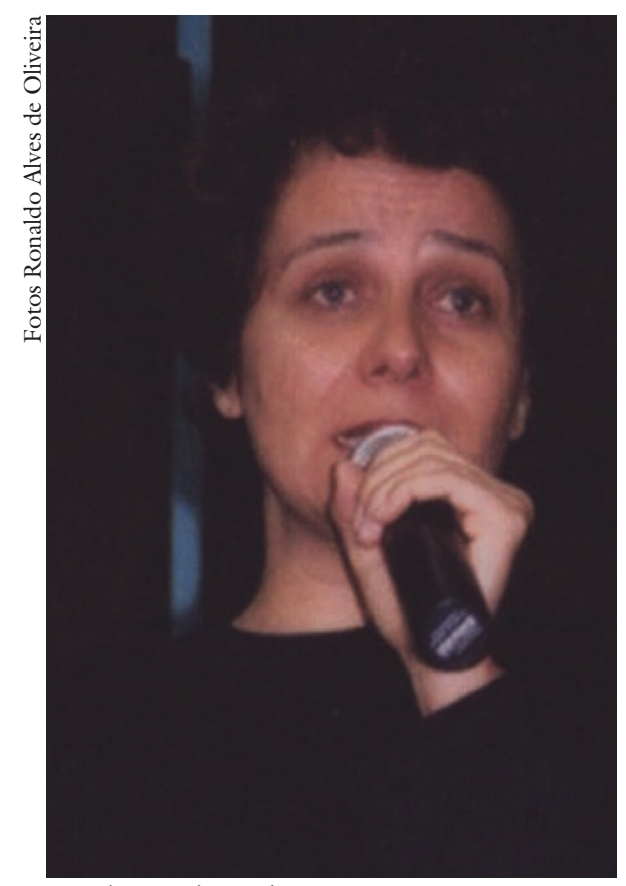

Elisa Almeida.

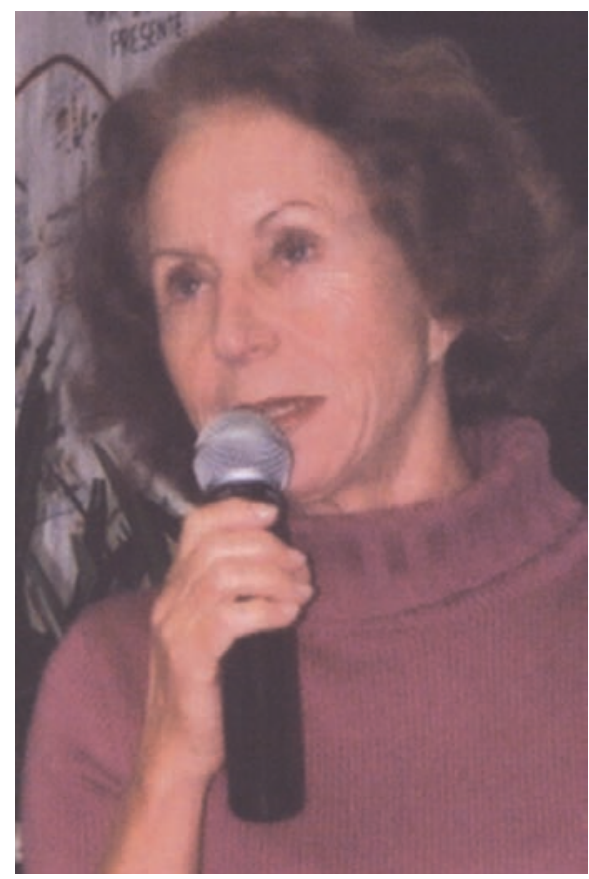

Auxiliadora Guimarães (Dôra).

da Silveira Guimarães, prima de Guimarães Rosa, com o objetivo de incentivar a leitura dos livros desse escritor. $\mathrm{O}$ grupo recebeu esse nome porque Miguilim era o apelido de Guimarães Rosa quando criança. Sua família morava em Cordisburgo, uma cidade pacata no interior de Minas Gerais. Seu pai possuía uma loja de "secos e molhados", como se dizia naquela época. Um amigo da família descobriu que o futuro escritor era míope. Quando o garoto passou a usar óculos, tomou gosto pela leitura e descobriu os detalhes do mundo e da natureza. Começou a apreciar os "causos" contados pelos velhos de Cordisburgo e vivia fazendo perguntas às pessoas. Posteriormente, ficou conhecida a sua mania de anotar as respostas que lhe eram dadas nas andanças pelo sertão.

Escreveu ele que os sertanejos são fabulistas por natureza, estando em seu sangue o dom para narrar estórias: "Desde pequenos estamos ouvindo as narrativas multicoloridas dos velhos, os contos e as lendas, e também nos criamos em um mundo que às vezes se assemelha a uma lenda cruel". E concluiu: "Deus meu! No sertão, o que pode uma pessoa fazer do seu tempo livre a não ser contar estórias".

O grupo dos Miguilins é formado por 52 pessoas - crianças, adolescentes e adultos. Possui um rico repertório que inclui trechos de livros de Guimarães Rosa, desde o primeiro livro, Sagarana até o último, Magma.

Para desvendar a formação dessa experiência singular em nossa vida cultural, entrevistamos em Cordisburgo as professoras Auxiliadora Guimarães (Dôra) e Elisa Almeida, buscando sobretudo conhecer as razões que levaram Calina Guimarães a criar os Miguilins e a traçar suas diretrizes. Em resumo, essas foram as informações. 
Dôra Guimarães - Como sou formada em Letras, optei por trabalhar com contos literários e poesias. Comecei a fazer isso em escolas, iniciando naquela em que eu lecionava. Depois conheci Elisa Almeida, que gostava de estórias de tradição oral, e passamos a trabalhar juntas. Em 1994, no Palácio das Artes, em Belo Horizonte, apresentamos textos com a temática do amor. Entre eles, havia narrativas de Marina Colassanti, Gabriel Garcia Márquez, Clarice Lispector e Guimarães Rosa. Chamei minha tia Calina Guimarães para nos assistir e ela ficou sabendo que formávamos contadores de estórias. Daí o convite para trabalharmos com as crianças em Cordisburgo.

Desde seu curso de Medicina, minha tia sempre morou em Juiz de Fora. Quando se aposentou, ao visitar Cordisburgo, encontrou o Museu meio abandonado. Por isso decidiu mudar-se para cá a fim de restaurá-lo. Conseguiu verbas da Secretaria de Cultura de Minas Gerais e decidiu fundar a Associação dos Amigos da Casa Guimarães Rosa.

\section{Estudos Avançados - Como é feita a seleção dos Miguilins?}

Elisa Almeida - Quem fazia a seleção era a Calina. Convidava os meninos e as meninas e os chamava para freqüentarem sua casa. Nas escolas os professores indicavam alunos, mas se algum desses manifestasse vontade de entrar no grupo também podia se inscrever.

Dôra Guimarães - Desde as primeiras turmas percebemos que não adiantava trabalhar com rapazes e moças na idade em que poderiam entrar na universidade, pois logo saíam de Cordisburgo. Decidimos então concentrar a formação dos Miguilins naqueles que estivessem cursando as quintas e sextas séries do ensino fundamental. Todavia, Calina Guimarães sempre entendeu que esse trabalho com os contadores de estórias é sobretudo uma maneira de ajudá-los e uma forma saudável de eles viverem a adolescência.

Por diversas razões, alguns adolescentes deixam o grupo durante o treinamento, o que é normal. Contudo, a maioria fica porque os Miguilins passaram a ser convidados para se exibirem em várias cidades - como São Paulo e Belo Horizonte -, o que aumentou o atrativo para a atuação nos grupos. Eles também recebem um pequeno cachê, embora nosso objetivo não seja ganhar dinheiro. Os que estão fazendo treinamento igualmente atuam como guias no Museu, dando informações sobre Guimarães Rosa e contando estórias para os turistas.

Ao lado disso, Calina Guimarães decidiu hospedar num apartamento em Belo Horizonte, na época do vestibular, os que se preparam para ingressar no ensino superior. Diante desse trabalho com os Miguilins, causa espanto o elevado índice de desenvolvimento cultural dos universitários que foram contadores de estórias em Cordisburgo.

Agora faremos uma nova seleção para o ingresso no grupo, porque muitos Miguilins completam o ensino médio e deverão sair de Cordisburgo. É uma pena, pois quando eles estão melhor preparados entendem que devem ir para as cidades onde há ensino superior. 


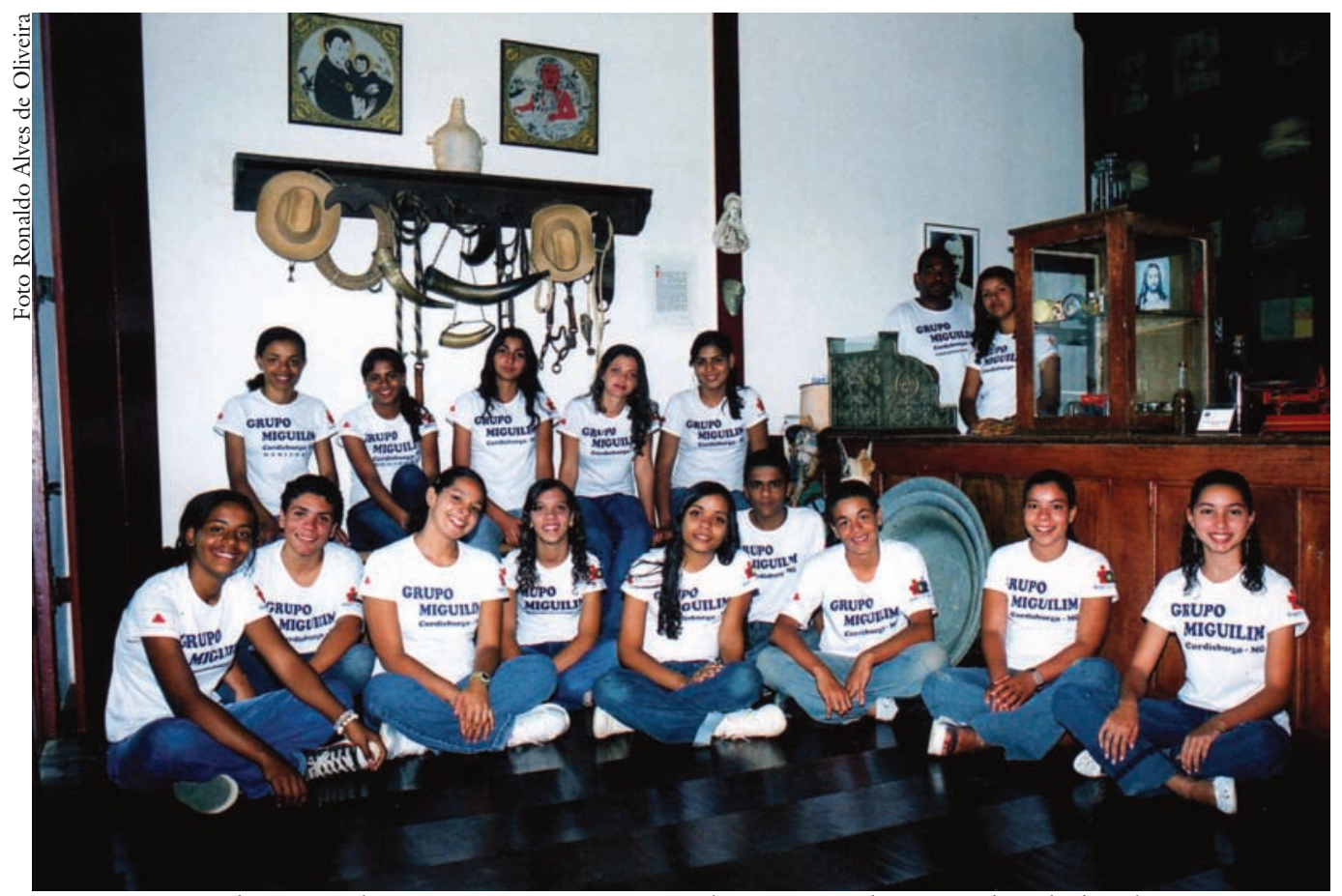

Um grupo de Miguilins com a camiseta que é a marca do contador de histórias.

Estudos Avançados - E a camiseta usada nos espetáculos, indicando que aquele adolescente é um contador de estórias? Só os Miguilins podem usá-la?

Elisa Almeida - Sim. E a camiseta é muito importante. Os alunos só a recebem depois de um ano e meio de treino. A camiseta é um distintivo e temos um ritual para entregá-la. Há também uma norma no estatuto: só podem contar estórias usando a camiseta. Não podem emprestá-la e também só podem vestila nos espetáculos. Quando entram na universidade deixam de ser Miguilim e devem devolver a camiseta.

\section{O fascínio da atividade de contar histórias}

Estudos Avançados - Como vocês analisam o trabalho dos Miguilins? Trata-se de uma declamação, tão usada antigamente, ou é uma encenação teatral? Em que medida vocês fogem um pouco da leitura dos textos de Guimarães Rosa?

Dôva Guimarães - Nosso trabalho parece realmente uma declamação. Mas é diferente desta porque aceita a intervenção do narrador. Ademais, os textos têm uma linguagem simples e linear. Algumas pessoas falam que recitamos os textos de Guimarães Rosa. Contudo, não queremos que identifiquem nosso trabalho como declamação ou recitação. Tentamos aproximar o máximo da fala do narrador da tradição oral. No entanto, isso é impossível na totalidade, porque o texto não é só oralidade. Fazemos um trabalho no meio-termo: não é só encenação e nem só declamação. No início, as pessoas ficam sem saber o que está acontecendo, mas acostumam o ouvido e entram na narração.

Talvez o que nos diferencie é que nós, enquanto contadoras de estórias, perseguimos a naturalidade o tempo inteiro. Temos o tempo da preparação do 


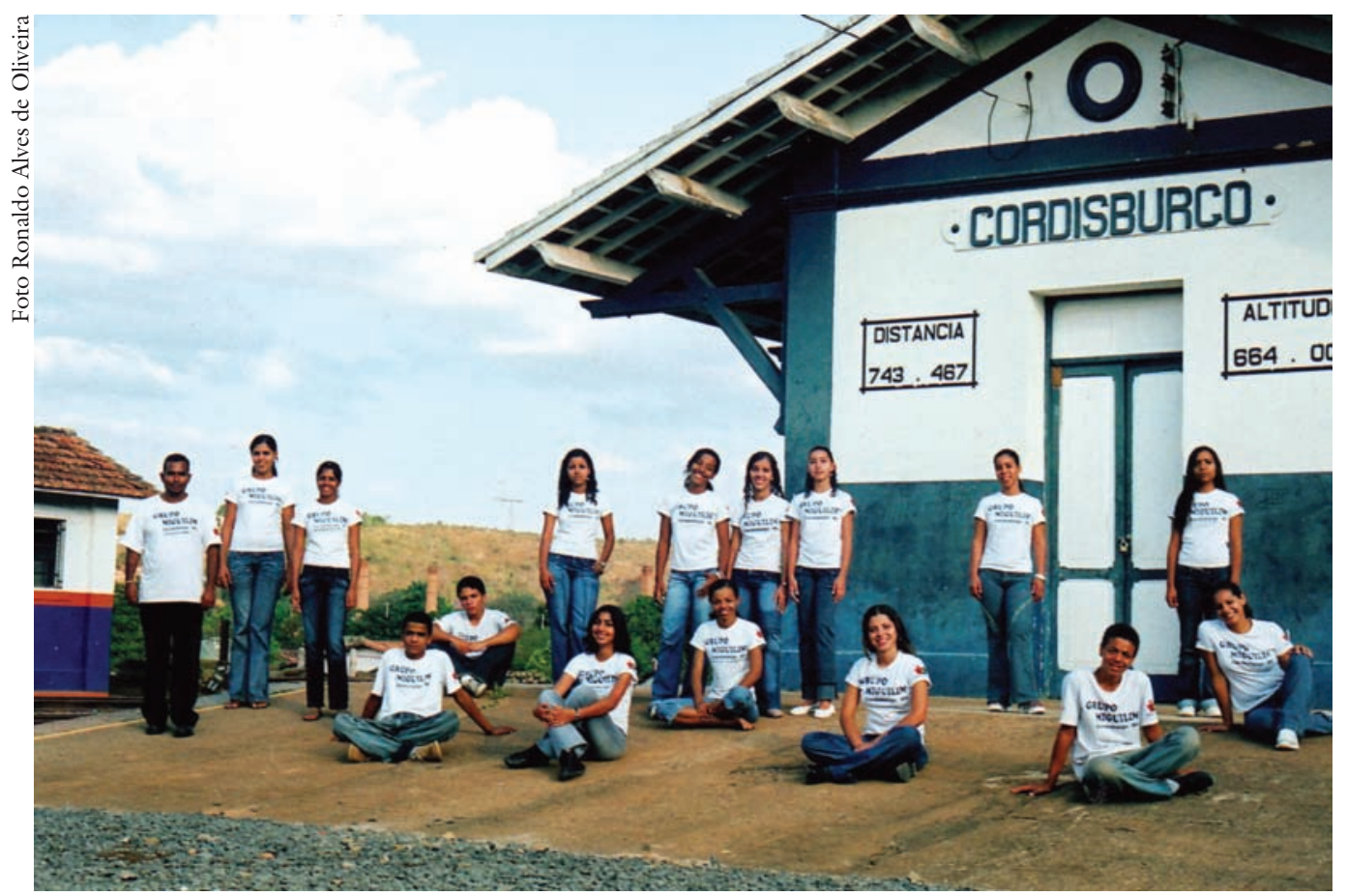

A cidade dos Miguilins, herdeiros de Guimarães Rosa.

texto, para decorá-lo. (Deixei de ter medo da palavra decorar quando entendi a raiz da expressão de cor, que significa de coração.) Isso é o que tentamos - falar com o coração. Nesse ponto, Guimarães Rosa é um prato cheio, pois consegue trabalhar a linguagem e ao mesmo tempo apresenta uma linguagem oral. Depois da fase de decorar e repetir o texto, este flui naturalmente da boca do contador de estórias.

Estudos Avançados - Depois de assisti-las duas vezes, acho que também há um aspecto de teatro, de encenação. Não é assim?

Dôra Guimarães - Sem dúvida. É o que falamos a nossos alunos: vocês não contam estórias como se estivessem transmitindo um "causo", numa mesa de bar. Vocês vão usar Guimarães Rosa e devem assumir o lado do narrador de estórias. Muita gente pergunta qual a diferença entre o contador de estórias e o ator. Existe diferença? Particularmente, gosto de pensar que em alguns momentos há uma diferença e, em outros momentos, não. O contador de estórias é o ator de um personagem, o narrador. Ele busca naturalidade em cima do texto que preparou, desenvolvendo nele esse lado de contador de estórias.

Estudos Avançados - Um texto de Pedro Nava poderia ser trabalhado da mesma forma?

Dôra Guimarães - Sim, inclusive já tivemos essa idéia. Em Belo Horizonte participei de dois trabalhos no Museu Abílio Barreto contando estórias da cidade.

Essas histórias de Guimarães Rosa, passadas nos Gerais, para mim, parecem terem sido criadas para o contador de estórias. Sempre imagino que ele, escrevendo, pensava na fala desse contador de "causos", só que a fala é unida a uma 
elaboração da linguagem que não permite a fluência desse relato de "causos". Porém, mesmo com toda elaboração, o texto roseano permite essa fluência, ao contrário de um texto, por exemplo, de Clarice Lispector, que é bem difícil, seco.

Estudos Avançados - Como é a remuneração de vocês? A Dôra já está aposentada e você, Elisa?

Elisa Almeida - Leciono numa escolinha em Belo Horizonte. Durante seis meses recebemos uma ajuda de duzentos reais por mês, pois obtivemos apoio da Brazil Fundation e do Santander Banespa. A partir do ano passado, o Museu passou a pagar a gasolina para virmos a Cordisburgo. Todavia, nosso trabalho acaba sendo voluntário. Nas vésperas da "semana roseana" viemos praticamente todas semanas, mas normalmente só de quinze em quinze dias. Em nossa ausência, os alunos maiores se reúnem com os menores. E há três coordenadores, também Miguilins, que treinam os outros colegas e trocam experiências.

\section{As "Caminhadas eco-literárias"}

Em Cordisburgo, uma das iniciativas mais singulares do trabalho em torno da literatura de Guimarães Rosa são as "Caminhadas eco-literárias", criadas e dirigidas por José Osvaldo dos Santos, o Brasinha. Esse comerciante é um expert sobre lugares e pessoas que aparecem nos livros do escritor. Aponta dados que apenas derivam da capacidade inventiva do autor de Grande sertão: veredas, mas indica a localização das referências do escritor a determinados lugares que realmente existem e que surgem no desenrolar dos contos e romances de Guimarães Rosa.

Brasinha, com 58 anos, nasceu em Sabará, e com um ano de idade veio para Cordisburgo. Terminou o ginásio e virou comerciante. Não conviveu com Guimarães Rosa, pois esse morou em sua cidade natal apenas em sua infância e só ocasionalmente retornou a ela. Contudo, como a obra do escritor está muito ligada a pessoas e fatos de Cordisburgo, Brasinha resolveu se dedicar ao minucioso estudo dessa literatura.

"Comecei a me interessar pela obra de Guimarães Rosa" - nos informou o comerciante - "a partir da pesquisa de algumas questões. Ou seja, localizar pessoas e lugares relacionados em seus textos. Esse empenho começou em conseqüência de um episódio. Tenho uma loja e, em frente a ela, havia uma barraca que era do Juca Bananeira. Anos atrás, falaram-me que Juca era um personagem de Guimarães Rosa mencionado na estória 'O burrinho pedrês'. Constatei a procedência daquela informação. Pensei, então, que seria útil esclarecermos dúvidas formuladas por muita gente sobre pessoas e fatos que aparecem nos romances e contos. Assim, tomei a peito a empreitada de obter esclarecimentos com as pessoas mais idosas e viajar para certos lugares com o objetivo de localizá-los.

Em razão disso, tive a idéia de envolver muitas pessoas na organização dessas 'Caminhadas eco-literárias'. Essa atividade recebeu tal denominação por- 

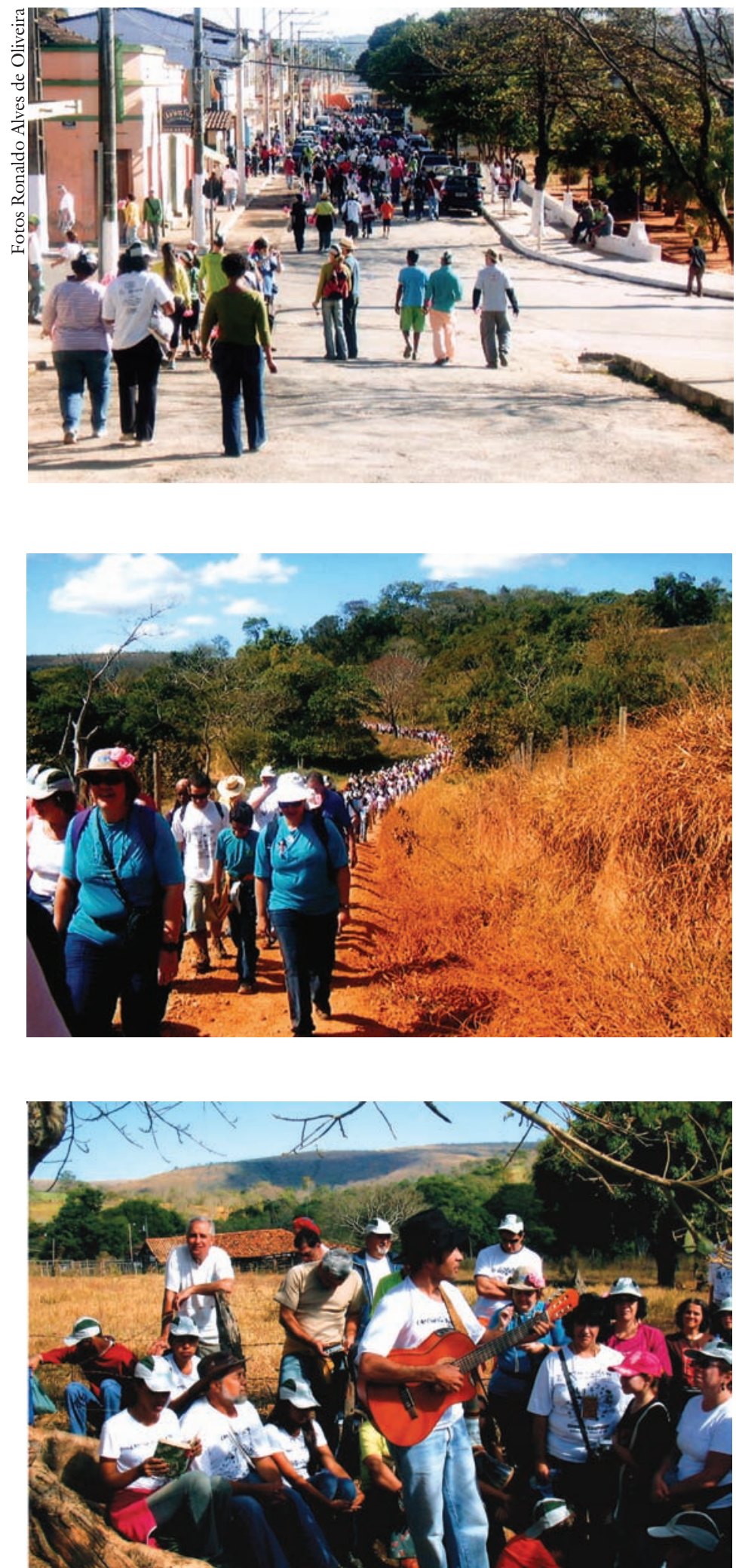

Na "Caminhada eco-literária" na cidade, em julho passado, participaram 400 pessoas. que a obra de Guimarães Rosa passa, em muitos momentos, a mensagem da importância do meio ambiente, particularmente do cerrado. $\mathrm{Na}$ primeira caminhada, realizada oito anos atrás, participaram somente cinqüenta pessoas. Na segunda, esse número dobrou. $\mathrm{Na}$ última 'semana roseana', em julho passado, na caminhada estavam quatrocentas pessoas. Além disso, durante o ano letivo diversas escolas pedem que organizemos essas caminhadas com seus estudantes. Resgatamos coisas importantes, porque muitas das estórias que aparecem em romances e livros de Guimarães Rosa foram colocadas em lugares aqui na região, como São Tomé, Cuba, Onça. Durante três anos, a caminhada girou em torno do conto ' $O$ recado do morro', curioso acidente geográfico localizado no município de Morro da Garça.

Posteriormente diversificamos a temática. Quando apresentamos ' $\mathrm{O}$ burrinho 
pedrês', fomos até a Fazenda da Ponte e Dôra Guimarães narrou a passagem da boiada no mesmo lugar que o escritor descreveu o episódio. No ano seguinte, na caminhada foi contada a estória dos ciganos e depois fomos até a fazenda onde se passa o conto 'Luas-de-mel', que foi narrado pelo Zé Maria, outro excelente contador de histórias. Organizamos caminhadas tendo como centro 'Corpo fechado', 'Histórias de ave', 'Palavra' e trechos do Grande sertão: veredas. Daqui para a frente, faremos a mesma coisa com temas como as reflexões de Riobaldo sobre Deus e o Diabo".

Fazendo um balanço dos resultados das caminhadas, Brasinha afirma que elas aproximaram a comunidade de Cordisburgo da literatura do grande escritor. E enfatiza que as pessoas acham muito interessante estar nos lugares descritos por ele e que as estórias são mais bem entendidas quando narradas nos próprios locais referidos nos contos.

Os que acompanham as caminhadas concluem que assistem e participam de um espetáculo teatral encenado não num recinto de um teatro, mas ao ar livre, espetáculo que vai se transferindo de um lugar para outro, de acordo com um enredo, preparado de conformidade com uma estória de Guimarães Rosa. Nesse trabalho, Brasinha recebe o decisivo apoio da Associação dos Amigos do Museu Casa de Guimarães Rosa e da Prefeitura de Cordisburgo, que empresta onibus para o transporte das pessoas até os locais onde são feitas as caminhadas. Além de Cordisburgo, elas já foram promovidas em outras cidades, como Morro da Garça, Alto Belo e Montes Claros. Em São Paulo, foram organizadas no Ibirapuera e no bairro de Pinheiros, percorrendo vários quarteirões, do Sesc até a igreja do bairro.

Marco Antônio Coelho, jornalista, é editor-executivo da revista Estudos Avançados. É autor de Os descaminhos do São Francisco (Paz e Terra, 2005. 272p).

@ - macoelho@that.com.br 